\title{
LETTER OF APPRECIATION
}

International Biophilia Rehabilitation Academy

President Taki TAKIZAWA Shigeo

(Chair of the WORKSHOP "BIOPHILIA 2011")

The International Biophilia Rehabilitation Academy holds the international conference in many countries, and contributes to the improvement of people's welfare through progress in rehabilitation medicine. The activity for the functional recovery of advanced-age disabled persons is appreciated by the governments of each country.

The workshop "Biophilia 2011" of The 9th International Biophilia Rehabilitation conference will be held in Bucharest, Romania this year. It is my sincerest desire to increase a cooperative and productive relationship in this field between our two nations in the future, starting with the success of this workshop.

This letter of appreciation is presented to the president of the International Biophilia Rehabilitation Academy, Professor Taki TAKIZAWA Shigeo. On behalf of the Romanian Government, I express deep gratitude for the efforts of the persons concerned who are in charge of holding the workshop.

\section{Petre Stoian}

Charge d' Affaires a.i.

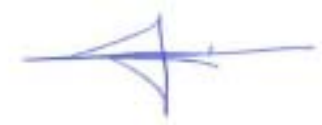

